\title{
Experimental study of moving liquid layer evaporation under gas flow into rectangular minichannel
}

\author{
Vyacheslav Maksimov ${ }^{1, *}$, Takhir Sharifulin ${ }^{1}$, Larisa Zhidkova ${ }^{1}$ and Karapet Eloyan ${ }^{2}$ \\ ${ }^{1}$ National Research Tomsk Polytechnic University, Tomsk, Russia \\ ${ }^{2}$ Institute of Thermophysics SB RAS, Novosibirsk, Russia
}

\begin{abstract}
The paper presents the experimental results on the mass evaporation rate from the moving liquid layer surface streamlined by the gas flow for different layer thicknesses. The maximum value of the mass evaporation rate was observed for a $5 \mathrm{~mm}$ liquid layer. Further increase in the thickness of the liquid layer causes a decrease in the mass evaporation rate. The assumption about the change in the balance of forces was made. A self-organized structure of the square-shaped spatial cells is found to form in the moving liquid layer streamlined by the gas flow. This structure has the most visible form at the maximum possible velocity of the air.
\end{abstract}

\section{Introduction}

Convective motion in a liquid layer arising due to turning up a liquid with higher density is known as Rayleigh-Bénard convection. Rayleigh-Bénard convection has been studied mainly in a horizontal liquid layer between solid walls [1]. Convection caused by the surface tension (Marangoni convection) has been studied in [2]. At the same time, the convection in a liquid layer with free boundary (the phase boundary between the liquid and the gas or vapor located above) is still less studied.

There are two basic mechanisms affecting the instability in systems with a free boundary. The mechanism of the instability arising due to the buoyancy force is more important for relatively thick liquid layers. While the instability caused by thermocapillary effect is dominant in thin liquid layer. Many works are devoted to the determination of the boundary of so-called "pure convection" caused by turning up a liquid with higher density (Rayleigh-Bénard convection). In systems with a free boundary there are two kinds of instability: stationary [3] and periodic [4]. In the case of Marangoni convection in systems with free boundary it was found that there are many kinds of instabilities. They are cells [5], free surface deformation leading to the appearance of dry spots [6], longitudinal [7], and transverse $[8,9]$ periodic instabilities. But the most common cases are in which there are two mechanisms of instability formation simultaneously.

Convection in the liquid layers which are continuously heated from below with a constant temperature gradient and excluding evaporation is most often studied [10]. There

\footnotetext{
*Corresponding author: author@email.org
} 
is a lack of studies devoted to evaporating liquid layers since evaporation greatly complicates the problem. Experimental studies devoted to research of evaporating singlecomponent liquid layer and observation of the convective flows formation in small amount of liquid have been conducted in [11]. Four basic modes of convection for the singlecomponent liquids have been analyzed in the work. For all liquids with $2 \mathrm{~mm}$ or less thickness, the dominant mode of convection is a mode with formation of cells. For moderately volatile liquids, such as alcohols, there is a pseudo stable flow pattern, temporary cells. There is either growth or reduction of cells or accidental movement of cells due to interaction with neighboring cells. For intensively evaporating liquids (for example, different types of ether), unstable state of liquid can be observed.

The influence of non-linear temperature profiles before convection on the order of the critical Marangoni number in the case of the flow caused by the surface tension in the evaporating liquid layer was analyzed using the linear stability theory [12]. It is found that in case of a strong non-linearity of the temperature profile, the critical Marangoni number may be much higher than for the corresponding linear temperature profile.

The evaporation in the liquid layer is mainly considered only as a means of cooling the surface layer. The role of evaporation is ignored in the problem of convective stability. There are very small numbers of experimental studies on the comparative analysis of the instability with a short-wave nature that may arise in volatile liquid layers. There are experimental results on the effect of the evaporation on the thermocapillary convection in thin liquid layer [13]. The evaporation was found to affect not only the cooling of the surface layer but also to be the driving force influencing the development of convective instability.

The dynamics of instabilities caused by the action of surface tension and interfacial phenomena of convection in two-layer system was studied in [14]. The analysis of the interaction between the natural convection, thermo-capillary convection and convection caused by the shear stress [15] was conducted. The analytical and numerical solution of a liquid flow in an open horizontal space under the influence of the gas flow was obtained. The topology of convective flows with non-deformable interphase boundary due to the impact of the inert gas flow is presented. The effect of the stress tangential component caused by the action of the gas flow was studied. The exact solutions of the stationary problem of convective flow with thermo capillary interfacial boundary in a horizontal liquid layer under the influence of the inert gas flow were obtained. It demonstrated the presence of a reverse flow with respect to the direction of gas flow near the interface.

It was shown theoretically and experimentally that the structural changes in the flow resulting to backward movement of the liquid film can occur under the action of thermocapillary forces arising due to the temperature gradient at the interface between liquid and gas [16].

Thermocapillary convection has a significant effect on the motion of the liquid in twophase systems [17]. Significant temperature differences at the interface cause waves, vortex and reversal flows, and can lead to rupture of the film [18].

It can be concluded based on the analysis of scientific publications [19-25] that the evaporation of the liquid film under the influence of the gas flow has not been studied at a level that would allow for predictive modeling of high-technology equipment with miniand micro-channels.

The dynamics of evaporation depending on the temperature of the two-phase system, gas flow velocity, liquid layer thickness, and, in addition, the influence of normal and shear stresses, thermocapillary effect, instabilities forming in the liquid on evaporation were studied in [26]. It is noted that the viscosity and surface tension depend on the temperature and lead to a change in the evaporation rate; by increasing the thickness of the liquid film, thermocapillary effect becomes the main factor of evaporation. In this case, causes of 
changes in the evaporation rate at different parameters cannot be explained from a physical point of view.

In view of the above, the study of the heat exchange processes in the interaction of the moving liquid film with a parallel gas flow is relevant.

The purpose of this study was to determine the dependence of the mass evaporation rate on the liquid layer thickness moving in minichannel under the action of the following gas flow.

\section{Experimental apparatus}

Experimental studies were conducted on the setup [27, 28] for the study of the dynamics of evaporation and convective flows in minichannel.

The conception of the experiment includes the application of previously tested methods [27] for studying heat and mass transfer across the interface between liquid and gas.

The experiments have been conducted under the atmospheric pressure in the test cell. The thickness of moving liquid layer was varied from 1 to $8 \mathrm{~mm}$. As a working liquid we used ethanol (95\% ppb mass). The evaporation surface blown by a gas flow (air) was $100 \mathrm{~mm}^{2}$ with $10 \times 10 \mathrm{~mm}$ cut in the plate. The gas flow rate was ranged from 100 to 1000 $\mathrm{ml} / \mathrm{min}$ with a $100 \mathrm{ml} / \mathrm{min}$ step, which corresponds to an average gas velocity from 0.014 $\mathrm{m} / \mathrm{sec}$ to $0.125 \mathrm{~m} / \mathrm{sec}$. The main influencing factors are summarized in Table 1 .

Table 1. The main influencing factors.

\begin{tabular}{|c|c|}
\hline Factors & Values \\
\hline Gas velocity, $\mathrm{m} / \mathrm{sec}$ & $0.014-0.125$ \\
\hline Interface area, $\mathrm{mm}^{2}$ & 100 \\
\hline Velocity of the moving liquid layer, $\mathrm{m} / \mathrm{sec}$ & $8.3 \cdot 10^{-5}$ \\
\hline Pressure in the circuit & atmospheric \\
\hline Liquid in the system & ethanol $(95 \% \mathrm{ppb}$ mass $)$ \\
\hline Gas in the system & air \\
\hline
\end{tabular}

\section{Results and discussion}

When conducting the experiment, the temperatures of the liquid and gas were kept constant. Figure 1 presents the dependence of the mass evaporation rate on the liquid layer thickness at the ethanol/air system temperature of $\mathrm{T}=20^{\circ} \mathrm{C}$ in the gas velocity range from 0.014 to $0.125 \mathrm{~m} / \mathrm{sec}$. The value of the mass flow rate is found to have a local maximum. An increase in the evaporation liquid layer thickness from 1 to $5 \mathrm{~mm}$ leads to an increase in the intensity of evaporation, which reaches a maximum at a $5 \mathrm{~mm}$ layer thickness. A further increase in the liquid layer thickness causes a decrease in the mass evaporation rate. 


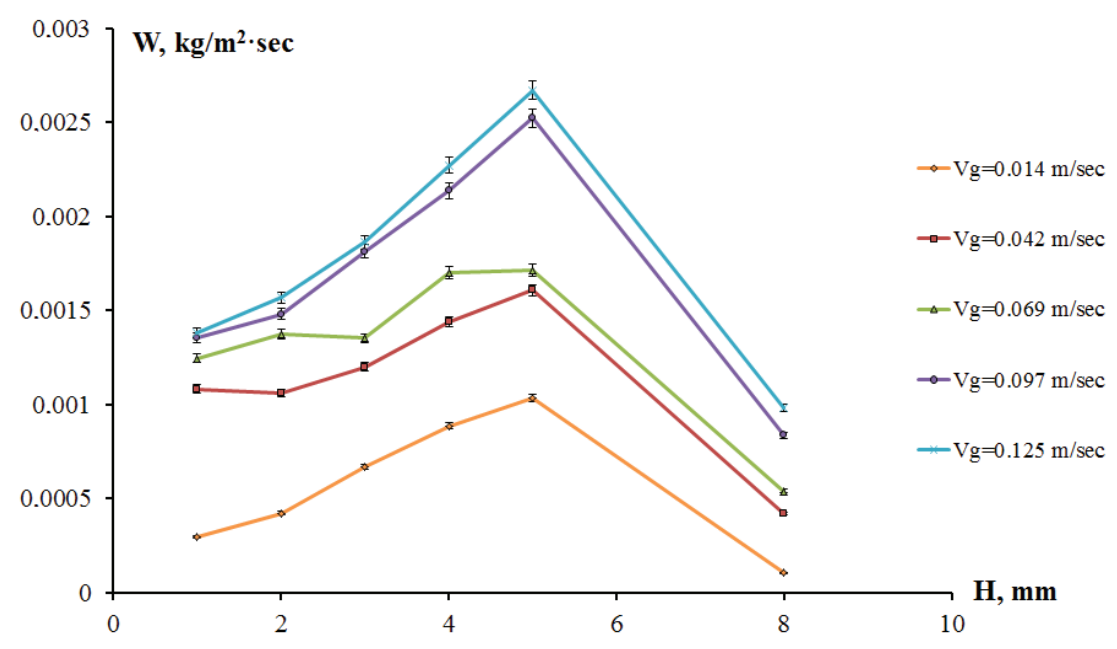

Fig. 1. Mass evaporation rate versus liquid layer thickness at the ethanol/air system temperature of $\mathrm{T}=20^{\circ} \mathrm{C}$.

Experimental dependences of the mass evaporation rate on the liquid layer thickness in the gas flow velocity range from 0.028 to $0.139 \mathrm{~m} / \mathrm{sec}$ at the ethanol/air system temperatures of $\mathrm{T}=30^{\circ} \mathrm{C}, \mathrm{T}=40^{\circ} \mathrm{C}, \mathrm{T}=50^{\circ} \mathrm{C}$ are presented in Fig. 2-4.

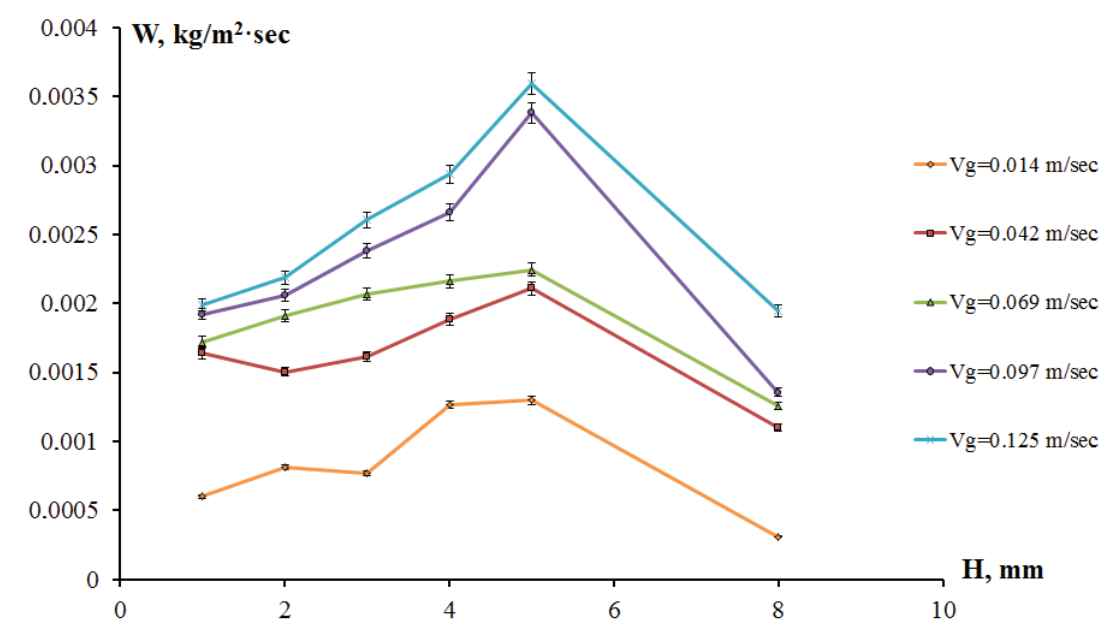

Fig. 2. Mass evaporation rate versus liquid layer thickness at the ethanol/air system temperature of $\mathrm{T}=30^{\circ} \mathrm{C}$.

According to analyses of presented dependences (Fig. 1-4) W is found to increase reaching a maximum value at a $5 \mathrm{~mm}$ liquid layer thickness. Further increase in the thickness of the liquid layer causes a decrease in the mass evaporation rate.

Most likely, it is due to the change in the balance of forces caused by thermocapillary effect, shear stresses, which appear because of the gas flow and natural convection. Natural convection is dependent on the liquid layer thickness. Possibly, there is some convection mode with the maximum evaporation rate for each liquid layer thickness and temperature of the liquid and gas. It should be noted that the geometrical dimensions of the rectangular channel through which the gas and liquid is transported can significantly affect the convection mode. 


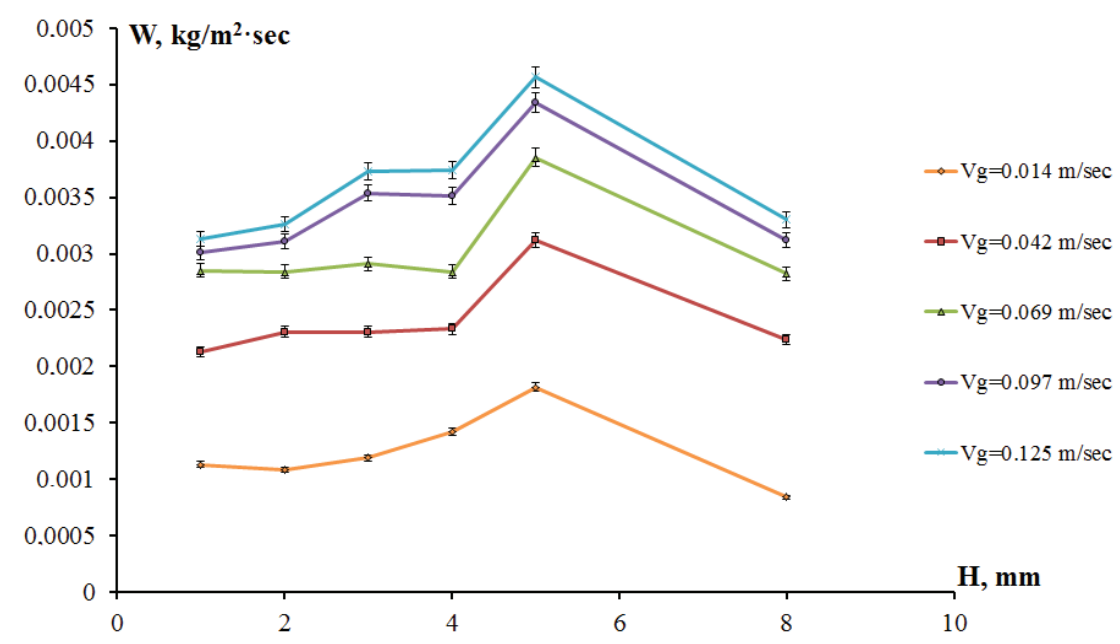

Fig. 3. Mass evaporation rate versus liquid layer thickness at the ethanol/air system temperature of $\mathrm{T}=40^{\circ} \mathrm{C}$.

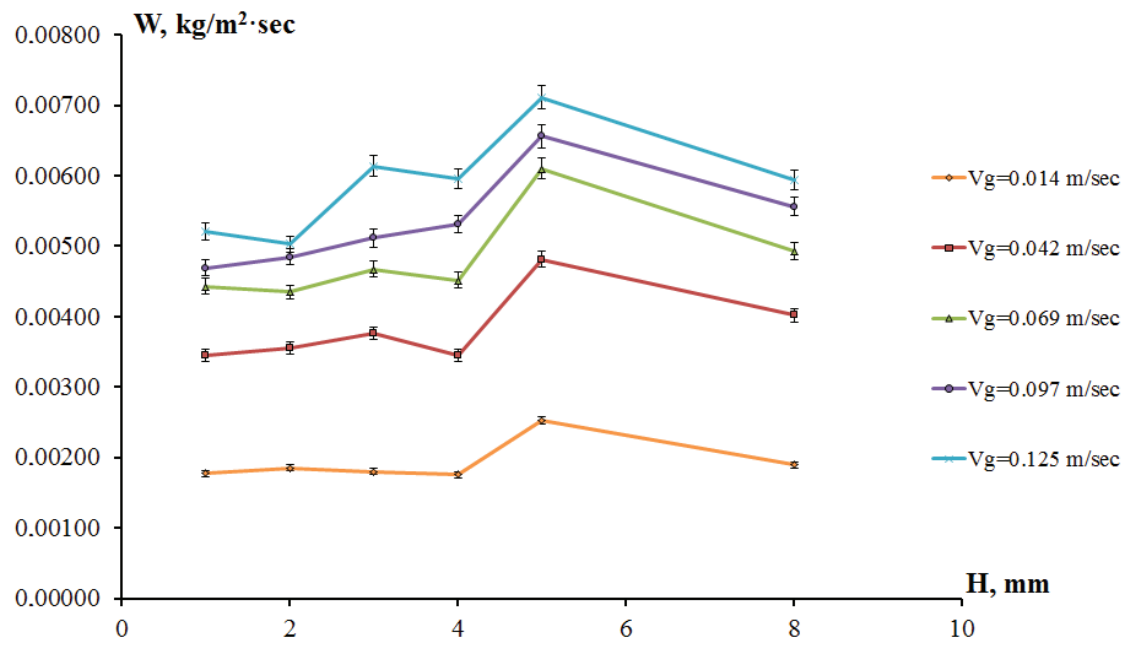

Fig. 4. Mass evaporation rate versus liquid layer thickness at the ethanol/air system temperature of $\mathrm{T}=50^{\circ} \mathrm{C}$.

The most common method for visualizing convective flows is the shadow method based on the temperature dependence of the refractive index. Cold downflows focus the light and look bright projected on the screen. And warm upward flows act dissipating and appear dark.

Photographic images of experimental studies obtained using the shadow method are shown in Table 2-3.

According to analyses of the photographic images a self-organized structure of the square-shaped spatial cells is found to form in the moving liquid layer streamlined by the gas flow. Formation of cells occurs in proportion to the average velocity of the air flow; at the maximum possible velocity of the air cells have the most visible form. 
Table 2. Photographic images of the interface at $\mathrm{T}=50^{\circ} \mathrm{C}(\mathrm{H}=1 \div 3 \mathrm{~mm})$.

\begin{tabular}{|l|l|l|l|l|l|l|l|}
\hline $1 \mathrm{~mm}$ & & $\mathrm{~V}_{\mathrm{g}}=0.014 \mathrm{~m} / \mathrm{sec}$ & $\mathrm{V}_{\mathrm{g}}=0.042 \mathrm{~m} / \mathrm{sec}$ & $\mathrm{V}_{\mathrm{g}}=0.069 \mathrm{~m} / \mathrm{sec}$ & $\mathrm{V}_{\mathrm{g}}=0.097 \mathrm{~m} / \mathrm{sec}$ & $\mathrm{V}_{\mathrm{g}}=0.125 \mathrm{~m} / \mathrm{sec}$ \\
\hline & & & & & & & \\
\hline
\end{tabular}

Table 3. Photographic images of the interface at $\mathrm{T}=50^{\circ} \mathrm{C}(\mathrm{H}=4 \div 8 \mathrm{~mm})$.

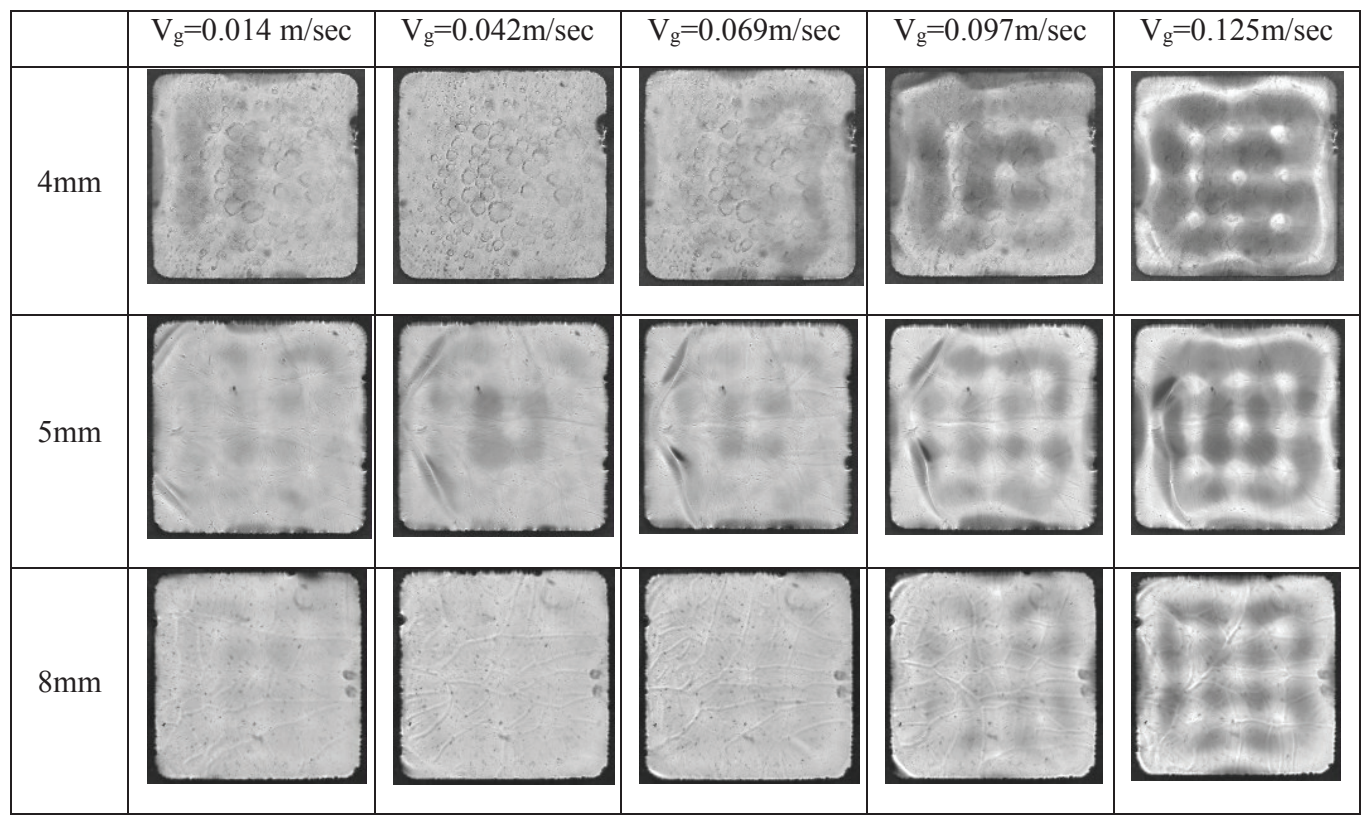

Also it is worth noting that at the $5 \mathrm{~mm}$ liquid layer thickness a regular structure in the form of liquid roller occurs from the side of the gas inlet. This structure becomes more visible with increasing gas flow velocity. Further increase in the liquid layer thickness up to $8 \mathrm{~mm}$ results in the disappearance of the structure, while the convective cells form at the interface.

In earlier work [29] the effect of the film structure on the evaporation intensity was studied. It was noted that various types of instabilities can increase the mass evaporation rate. Thus, the occurrence of the maximum evaporation rate of liquid layer with a $5 \mathrm{~mm}$ 
thickness, and reduce in the evaporation rate when further increase in the liquid layer thickness can be caused by a regular structure, which is formed at a $5 \mathrm{~mm}$ layer thickness.

The research was supported by the Ministry of Education and Science of Russia (Agreement No 14.613.21.0011, project identifier RFMEFI61314X0011).

\section{References}

1. J. R. A. Pearson, J. Fluid Mech. 4, 489 (1958)

2. I. Simanovskii, Fluid Dyn. 14, 637 (1979)

3. P. Colinet, J.C. Legros. Phys. Fluids 6, 2631 (1994)

4. K. Eckert, M. Bestehorn, A. Thess. J. Fluid Mech. 356, 155 (1998)

5. S. J. Van-Hook, M. F. Schatz, W. D. McCormick, J. B. Swift, H. Swinney. J. Fluid Mech. 345, 45 (1997)

6. C. V. Sterling, L. E. Scriven. AIChE J. 5, 514 (1959)

7. P. L. Garcia-Ybarra, M. G. Velarde. Phys. Fluids 30, 1649 (1987)

8. J. C. Berg, M. Boudart and A. Acrivos. J. Fluid Mech. 24, 721 (1966)

9. J. C. Berg, A. Acrivos, M. Boudart, Evaporative convection, Advanced Chemical Engineering, Vol. 6, Ed. By T. B. Drew et al. (Academic Press, New York, 1966)

10. O.A. Kabov, D.V. Zaitsev, Multiphase Science and Technology 21, 249 (2009)

11. A. Vidal, A. Acrivos. I \& EC Fundam. 7, 53 (1968)

12. N. Zhang, A.-T. Chai. Exp. Heat Transfer 11, 187 (1998)

13. A. Nepomnyaschy, I. Simanovskii, L. Braverman. J. Fluid Mech. 442, 141 (2001)

14. C. S. Iorio, O. N Goncharova, O. A. Kabov. Microgravity Sci. Technol. 23, 373 (2011)

15. O. A. Kabov, B. Scheid, I. A. Sharina, J. Legros. Int. J. Therm. Sci. 41, 664 (2002)

16. M. A. Frank, O. A. Kabov. Phys. Fluid 18, 032107, 2006.

17. P. Colinet, J.-C. Legros, M. G. Velarde, Nonlinear Dynamics of Surface - Tension Driven Instabilities (Wiley-VCH, Berlin, 2001)

18. O. A. Kabov, E. A. Chinnov. High Temp. 39, 703 (2001)

19. V. E. Nakoryakov, S. L. Elistratov, S. Y. Misyura. J. Eng. Thermophys-Rus. 20, 338 (2011)

20. V. E. Nakoryakov, S. Y. Misyura, S. L. Elistratov, A. Y. Manakov, A. A. Sizikov. J. Eng. Thermophys-Rus. 22, 169 (2013)

21. V.E. Nakoryakov, S.Ya. Misyura, S.L. Elistratov, R.A. Dekhtyar. J. Eng. ThermophysRus. 23, 257 (2014)

22. G. V. Kuznetsov, N. I. Kurilenko, V. I. Maksimov, G. Ya. Mamontov, T. A. Nagornova. J. Eng. Phys. Thermophys. 86, 519 (2013)

23. G. V. Kuznetsov, P. A. Strizhak. J. Eng. Phys. Thermophys. 87, 103 (2014)

24. G.V. Kuznetsov, D.V. Feoktistov, E.G. Orlova, K.A. Batishcheva, Colloid J. 78, 335 (2016)

25. G. Kuznetsov, D. Feoktistov, E. Orlova, Thermophys. Aeromech, 23, 17 (2016)

26. D. V. Feoktistov, E. G. Orlova, V. D. Velicanov. MATEC Web of Conferences 23, 01056 (2015)

27. Y. V. Lyulin, D. V. Feoktistov, I. A. Afanas'ev, E. S. Chachilo, O. A. Kabov, G. V. Kuznetsov. Tech. Phys. Lett+ 41, 665 (2015)

28. I. Afanasyev, E. Orlova, D. Feoktistov. EPJ Web of Conferences 82, 01054 (2015)

29. D. V. Zaitsev, D. A. Rodionov, O. A. Kabov. Technical Physics Letters 35, 680 (2009) 